Proyecciones Journal of Mathematics

Vol. 41, No 1 , pp. 217-247, February 2022.

Universidad Católica del Norte

Antofagasta - Chile

\title{
Eigenvalue problem of an impulsive differential equation governed by the one-dimensional p-Laplacian operator
}

\author{
Mohamed Bouabdallah \\ Mohammed First University, Morocco \\ Omar Chakrone \\ Mohammed First University, Morocco and \\ Mohammed Chehabi \\ Mohammed First University, Morocco \\ Received: January 2021. Accepted : October 2021
}

\begin{abstract}
In this paper we study a nonlinear boundary eigenvalue problem governed by the one-dimensional p-Laplacian operator with impulse, we give some properties of the first eigenvalue $\lambda_{1}$ and we prove the existence of eigenvalues sequence $\left\{\lambda_{n}\right\}_{n \in \mathbf{N} *}$ by using the LusternikSchnirelman principle, as well as by the characterization of the sequence of eigenvalues, we discuss the strict monotonicity of the first eigenvalue and we prove that the eigenfunction corresponding to second eigenvalue $\lambda_{2}$ changes sign only once on $[0,1]$.
\end{abstract}

Keywords: Eigenvalue; Eigenfunction; Impulsive Differential Equation; p-Laplacian; Lusternik-Schnirelman principle.

MSC(2020): 35R12,35A15,35P30. 


\section{Introduction}

Impulsive differential equations describe several phenomena in many fields. The idea of studying processes which can change state suddenly is natural and appears to be a good model for some applications in real world. For example, one of these applications cited in [1], is a pharmacokinetic model, involving first-order processes for drug release, this last is known as KrugerThiemer model. In this model the authors assume that the drug taken by a patient is nearly digested. Thus the time of the very process of absorbing is abandoned. Such a model of the process leads to impulsive differential equations, with impulses which take place when the drug is taken. Impulsive differential equation also study models in epidemiology [2], chemistry [3], economics [4], optimal control theory [5], nonlinear mechanics [6]. For the general theory of impulsive differential equations, we refer the reader to the references [7] and [8]. Some approaches have been used to study such problems in the literature. These approaches include the degree theory [9], the techniques of upper and lower solutions [10], and the fixed point theorems [11]. On the other hand, many researchers have used a variational method to the existence and multiplicity of solutions with impulsive effect (see [12], [13], [14], [15], [16] and [17]). The spectrum of the equations that involve the one-dimensional p-Laplacian operator with the different boundary condition, has been studied by several authors, for literature we quote here some works [18], [19], [20] and [21].

In the latter the authors studied the linear eigenvalue problem of the second order impulsive differential equation

$$
\begin{gathered}
-\left(p(t) u^{\prime}(t)\right)^{\prime}+q(t) u(t)=\lambda \rho(t) u(t), t \neq t_{k}, \text { a.e. } t \in J, \\
\Delta u^{\prime}\left(t_{k}\right)=a_{k} u\left(t_{k}\right), k=1, \ldots, i
\end{gathered}
$$

with the Dirichlet boundary conditions

$$
u(0)=u(1)=0,
$$

where the functions $\rho(t), q(t)$ and $p(t)$ are such that $\rho \in C(J,[0,+\infty[), q \in$ $C\left(J,\left[0,+\infty[)\right.\right.$ and $p \in C^{1}(J,[\delta,+\infty[)$, where $J=[0,1]$ and $\delta$ is a positive constant. $\Delta u^{\prime}\left(t_{k}\right)=u^{\prime}\left(t_{k}^{+}\right)-u^{\prime}\left(t_{k}^{-}\right), 0=t_{0}<t_{1}<t_{2}<\ldots<t_{i}<t_{i+1}=1$, $u^{\prime}\left(t_{k}^{+}\right)$and $u^{\prime}\left(t_{k}^{-}\right)$represents the right limit also the left one of $u^{\prime}(t)$ at $t_{k}$ respectively. In [21], the authors characterized the first eigenvalue $\lambda_{1}$ related to the problem $(1.1)-(1.3)$, by 
(1.4) $\lambda_{1}=\inf \left\{\int_{0}^{1}\left[p(t)\left(u^{\prime}(t)\right)^{2}+q(t)(u(t))^{2}\right] d t+\sum_{k=1}^{i} a_{k}\left(u\left(t_{k}\right)\right)^{2} \mid u \in \Omega_{1}\right\}$,

where $\Omega_{1}=\left\{u \in H_{0}^{1}([0,1]): \int_{0}^{1} \rho(t)(u(t))^{2} d t=1\right\}$.

They have shown that the infimum $\lambda_{1}$ in (1.4) is achieved at some $u \in \Omega_{1}$. Moreover, the latter is an eigenfunction associated to $\lambda_{1}$ which has a constant sign. Also, they have established the existence of an eigenvalues sequence for the problem (1.1) - (1.3) that is unbounded, and when $a_{k}=0$ for all $k=1,2, \ldots, i$, the problem $(1.1)-(1.3)$ becomes an eigenvalue problem of the following ordinary differential equation

$$
\begin{aligned}
& -\left(p(t) u^{\prime}(t)\right)^{\prime}+q(t) u(t)=\lambda \rho(t) u(t), t \in J \\
& u(0)=u(1)=0 .
\end{aligned}
$$

Several results have been obtained on this type of eigenvalue problems of differential equations, see, for instance, [22], [23] and [24]. A principal result is that (1.5) - (1.6) has a non-decreasing sequence of eigenvalues $\left\{\lambda_{n}\right\}_{n \in \mathbf{N}^{*}}$ which tend to $\infty$ as $n \longrightarrow \infty$. More precisely, in [24] the authors studied a eigenvalue problems of differential equations with impulsive effects which is given as below

by

$$
\begin{aligned}
& \left.-p(t) u^{\prime}(t)\right)^{\prime}+q(t) u(t)=\lambda \rho(t) u(t), t \in[0, a[\cup] a, b], \\
& u\left(a^{-}\right)=\alpha u\left(a^{+}\right), u^{\prime}\left(a^{-}\right)=\beta u^{\prime}\left(a^{+}\right), \\
& u(0)=u(b)=0 .
\end{aligned}
$$

They proved that the eigenvalue problem (1.7) - (1.9) has an unbounded sequence of eigenvalues $\left\{\lambda_{n}\right\}_{n \in \mathbf{N}^{*}}$. In the present paper, we will study the general case of problem $(1.1)-(1.3)$ when $p \neq 2$. That is, we consider the following nonlinear eigenvalue problem with impulsive effects

$$
\begin{aligned}
& -\left(r(t)\left|u^{\prime}(t)\right|^{p-2} u^{\prime}(t)\right)^{\prime}+s(t)|u(t)|^{p-2} u(t)=\lambda m(t)|u(t)|^{p-2} u(t), t \neq t_{k}, \text { a.e. } t \in J, \\
& \Delta_{p} u^{\prime}\left(t_{k}\right)=a_{k}\left|u\left(t_{k}\right)\right|^{p-2} u\left(t_{k}\right), k=1, \ldots, i, \\
& u(0)=u(1)=0
\end{aligned}
$$

where $s(t), m(t)$ and $r(t)$ are such that $s \in C(J] 0,,+\infty[), m \in C(J] 0,,+\infty[)$, $r \in C^{1}\left(J,\left[\delta,+\infty[), J=[0,1], \delta\right.\right.$ a positive constant and $\Delta_{p} u^{\prime}\left(t_{k}\right)=$ $\left|u^{\prime}\left(t_{k}^{+}\right)\right|^{p-2} u^{\prime}\left(t_{k}^{+}\right)-\left|u^{\prime}\left(t_{k}^{-}\right)\right|^{p-2} u^{\prime}\left(t_{k}^{-}\right)$. 
A function $u \in W_{0}^{1, p}([0,1])$ is not a solution of $(1.10)-(1.12)$, because this latter is not continuous throughout the interval $J=[0,1]$.

So, let's define a set $\Gamma=\left\{u \in W_{0}^{1, p}([0,1]):\left.u\right|_{] t_{k}, t_{k+1}[} \in W^{2, p}(] t_{k}, t_{k+1}[), k=\right.$ $0,1, \ldots, i\}$, which makes it possible to give a meaning to the solution of the problem (1.10) - (1.12).

Motivated by [21], we will establish some new properties for the eigenvalue problem (1.10)-(1.12). This paper is organized as follows. In Section 2 , we present some preliminary results. In Section 3, the main results of this paper will be presented.

\section{Preliminaries}

Let $W_{0}^{1, p}([0,1])$ and $L^{p}([0,1])$ respectively be the Sobolev and Lebesgue spaces equipped by the norms

$$
\begin{gathered}
\|u\|=\left(\int_{0}^{1}\left|u^{\prime}(t)\right|^{p} d t\right)^{\frac{1}{p}}, \text { for all } u \in W_{0}^{1, p}([0,1]) \text { and }\|u\|_{L^{p}}=\left(\int_{0}^{1}|u(t)|^{p} d t\right)^{\frac{1}{p}}, \\
\text { for all } u \in L^{p}([0,1]) .
\end{gathered}
$$

Lemma 2.1. The impulsive differential equation (1.10), (1.11) with initial value condition

$$
u(0)=u_{0}, u^{\prime}(0)=\overline{u_{0}}
$$

has a unique solution. Denote the initial value problem (1.10), (1.11) and (2.1) by $\operatorname{IVP}\left(u_{0}, \overline{u_{0}}\right)$.

Proof. Let $y(t)=r(t)\left|u^{\prime}(t)\right|^{p-2} u^{\prime}(t)=r(t) \Phi_{p}\left(u^{\prime}(t)\right)$ and $h(t)=s(t)-$ $\lambda m(t)$, where $\Phi_{p}(s)=|s|^{p-2} s$ if $s \neq 0, \Phi_{p}(0)=0, p>1$, and $\Phi_{q}=\Phi_{p}^{-1}$ with $\frac{1}{p}+\frac{1}{q}=1$. Then, for $k=1$, the problem $\operatorname{IVP}\left(u_{0}, \overline{u_{0}}\right)$ is lied as follows

$$
\left\{\begin{array}{l}
y^{\prime}(t)=h(t)|u(t)|^{p-2} u(t), u^{\prime}(t)=\Phi_{q}\left(\frac{y(t)}{r(t)}\right), t \neq t_{1} \text { and } t \in[0,1] \\
\Phi_{p}\left(u^{\prime}\left(t_{1}^{+}\right)\right)-\Phi_{p}\left(u^{\prime}\left(t_{1}^{-}\right)\right)=a_{1}\left|u\left(t_{1}\right)\right|^{p-2} u\left(t_{1}\right), \\
u(0)=u_{0}, u^{\prime}(0)=\overline{u_{0}} .
\end{array}\right.
$$


We reformulate the problem (2.2) to a Cauchy problem through which we distinguish two cases.

Firstly, when $t \in\left[0, t_{1}[\right.$, we have the following Cauchy problem

$$
\left\{\begin{array}{l}
X_{1}^{\prime}(t)=f\left(t, X_{1}(t)\right), t \in\left[0, t_{1}[\right. \\
X_{1}(0)=(y(0), u(0))^{T}
\end{array}\right.
$$

where $X_{1}(t)=(y(t), u(t))^{T}$ and $f\left(t, X_{1}(t)\right)=\left(h(t) \Phi_{p}(u(t)), \Phi_{q}\left(\frac{y(t)}{r(t)}\right)\right)^{T}$ which is locally Lipschitzian with respect to the second variable $X_{1}$ in a neighborhood $V_{1}$ which contains $X_{1}(0)$. In fact, we provide the space $\mathbf{R}^{2}$ by the Euclidean norm and let $W(t)=(y(t), u(t))^{T}, Z(t)=(z(t), v(t))^{T} \in V_{1}$, such that we have

$$
\begin{aligned}
& \|f(t, W(t))-f(t, Z(t))\|_{2} \\
& =\left\|h(t)\left(\Phi_{p}(u(t))-\Phi_{p}(v(t))\right), \Phi_{q}\left(\frac{y(t)}{r(t)}\right)-\Phi_{q}\left(\frac{z(t)}{r(t)}\right)\right\|_{2} \\
& =\sqrt{h^{2}(t)\left|\Phi_{p}(u(t))-\Phi_{p}(v(t))\right|^{2}+\left|\Phi_{q}\left(\frac{y(t)}{r(t)}\right)-\Phi_{q}\left(\frac{z(t)}{r(t)}\right)\right|^{2}} \\
& \leq \sqrt{h^{2}(t) K_{p}^{2}|u(t)-v(t)|^{2}+K_{q}^{2}\left|\frac{y(t)}{r(t)}-\frac{z(t)}{r(t)}\right|^{2}} \\
& \leq \sqrt{h_{+}^{2} K_{p}^{2}|u(t)-v(t)|^{2}+\frac{K_{q}^{2}}{\delta^{2}}|y(t)-z(t)|^{2}} \\
& \leq K \sqrt{|u(t)-v(t)|^{2}+|y(t)-z(t)|^{2}}=K\|W(t)-Z(t)\|_{2}
\end{aligned}
$$

where $h_{+}=\max _{t \in[0,1]} h(t), K=\sqrt{\max \left(h_{+}^{2} K_{p}^{2}, \frac{K_{q}^{2}}{\delta^{2}}\right)}$, as well that $K_{p}$ and $K_{q}$ are the Lipschitz constants of $\Phi_{p}$ and $\Phi_{q}$ respectively.

Then by Cauchy-Lipschitz theorem, we have the existence and uniqueness of solution in a neighborhood which contains 0 .

Finally, when $t \in\left[t_{1}, 1\right]$, we have a new Cauchy problem that is given as follows

$$
\left\{\begin{array}{l}
X_{2}^{\prime}(t)=f\left(t, X_{2}(t)\right), t \in\left[t_{1}, 1\right] \\
X_{2}\left(t_{1}\right)=\left(y\left(t_{1}\right), u\left(t_{1}\right)\right)^{T}
\end{array}\right.
$$

where $y\left(t_{1}\right)=r\left(t_{1}\right) \Phi_{p}\left(u^{\prime}\left(t_{1}\right)\right), u\left(t_{1}\right)=u\left(t_{1}^{-}\right)$and $u^{\prime}\left(t_{1}\right)=u^{\prime}\left(t_{1}^{-}\right)+a_{1} u\left(t_{1}\right)$. 
Similarly to the above, by applying the Cauchy-Lipschitz theorem we show the existence and uniqueness of solution in a neighborhood which contains $t_{1}$. Thus, for $k=1$, the problem (2.2) has a unique solution as follows

$$
X(t)=\left\{\begin{array}{l}
X_{1}(t), \text { if } t \in\left[0, t_{1}[\right. \\
X_{2}(t), \text { if } t \in\left[t_{1}, 1\right] .
\end{array}\right.
$$

The other cases $k=2,3, \ldots, i$ are treated in the same way as in the case $k=1$. Consequently, we have the existence and uniqueness of solution for the problem (2.2), which is given as follows

$$
X(t)=\left\{\begin{array}{l}
\overline{X_{1}}(t), t \in\left[0, t_{1}[\right. \\
\overline{X_{2}}(t), t \in\left[t_{1}, t_{2}[\right. \\
\vdots \\
\left.\left.\overline{X_{n+1}}(t), t \in\right] t_{n}, 1\right] .
\end{array}\right.
$$

Lemma 2.2. Let $y$ and $z$, the two solutions of (1.10), (1.11) with the same value $\lambda$. Then, there exists a constant $c$ such that $y=c z$ or $z=c y$.

Proof. If $y^{\prime}(0)=z^{\prime}(0)$, by Lemma 2.1, we have $y(t)=z(t)$. If $y^{\prime}(0) \neq$ $z^{\prime}(0)$, then at least one of $y^{\prime}(0)$ and $z^{\prime}(0)$ is not equal to zero. Choose $y^{\prime}(0) \neq$ 0 and let $c=z^{\prime}(0) / y^{\prime}(0)$. Since $y$ is a unique solution of $\operatorname{IVP}\left(0, y^{\prime}(0)\right), c y$ is a unique solution of $\operatorname{IVP}\left(0, c y^{\prime}(0)\right)$. On the other hand, $z$ is a unique solution of $\operatorname{IVP}\left(0, z^{\prime}(0)\right)$. Thus, $z=c y$.

Lemma 2.3. Let $u \in W_{0}^{1, p}([0,1])$, then

$$
\max _{t \in[0,1]}|u(t)|^{p} \leq \frac{1}{2^{p}}\|u\|^{p}
$$

Proof. $\quad$ Let $u(\xi)=\max _{t \in[0,1]}|u(t)|$ with $\left.\xi \in\right] 0,1\left[\right.$ and $\frac{1}{p}+\frac{1}{q}=1$. By Hölder's inequality, we have

$$
|u(\xi)|^{p} \leq(1-\xi)^{\frac{p}{q}} \int_{\xi}^{1}\left|u^{\prime}(t)\right|^{p} d t \text { and }|u(\xi)|^{p} \leq(\xi)^{\frac{p}{q}} \int_{0}^{\xi}\left|u^{\prime}(t)\right|^{p} d t
$$


which implies that

$$
\left[\frac{1}{\xi^{\frac{p}{q}}}+\frac{1}{(1-\xi)^{\frac{p}{q}}}\right]|u(\xi)|^{p} \leq \int_{0}^{1}\left|u^{\prime}(t)\right|^{p} d t .
$$

We consider the function $g$ defined on $] 0,1\left[\right.$ by $g(\xi)=\left[\frac{1}{\xi^{\frac{p}{q}}}+\frac{1}{(1-\xi)^{\frac{p}{q}}}\right]$, for all $\xi \in] 0,1[$.

We see that $g$ is differentiable on $] 0,1\left[\right.$ with $g^{\prime}(\xi)=\frac{p}{q}\left[\frac{(1-\xi)^{\frac{p}{q}-1}}{(1-\xi)^{\frac{2 p}{q}}}-\frac{\xi^{\frac{p}{q}-1}}{\xi^{\frac{2 p}{q}}}\right]$, for all $\xi \in] 0,1[$.

In addition, $g^{\prime}(\xi)=0$ if and only if $\xi=\frac{1}{2}$, then $g$ admits a minimum at $\xi=\frac{1}{2}$. So, we have $g(\xi) \geq g\left(\frac{1}{2}\right)=2^{\frac{p}{q}+1}=2^{p}$ and $|u(\xi)|^{p} \leq \frac{1}{2^{p}} \int_{0}^{1}\left|u^{\prime}(t)\right|^{p} d t$, for all $\left.\xi \in\right] 0,1[$.

Hence,

$$
\max _{t \in[0,1]}|u(t)|^{p} \leq \frac{1}{2^{p}}\|u\|^{p}
$$

Definition 2.1. For $u \in W_{0}^{1, p}([0,1])$, we define the norm

$$
\|u\|_{1, p}=\left(\int_{0}^{1}\left[r(t)\left|u^{\prime}(t)\right|^{p}+s(t)|u(t)|^{p}\right] d t\right)^{\frac{1}{p}} .
$$

Lemma 2.4. For the space $W_{0}^{1, p}([0,1])$, the norms $\|u\|_{1, p}$ and $\|u\|$ are equivalent, and there is $c_{\infty}>0$ such that $\|u\|_{\infty} \leq c_{\infty}\|u\|$.

Proof. Let $\|r\|_{\infty}=\max _{t \in[0,1]} r(t)$ and $\|s\|_{\infty}=\max _{t \in[0,1]} s(t)$. We have

$$
\begin{aligned}
\|u\|_{1, p} & =\left(\int_{0}^{1}\left[r(t)\left|u^{\prime}(t)\right|^{p}+s(t)|u(t)|^{p}\right] d t\right)^{\frac{1}{p}} \geq\left[\int_{0}^{1} r(t)\left|u^{\prime}(t)\right|^{p} d t\right]^{\frac{1}{p}} \\
& \geq \delta^{\frac{1}{p}}\left[\int_{0}^{1}\left|u^{\prime}(t)\right|^{p} d t\right]^{\frac{1}{p}} \\
& =\delta^{\frac{1}{p}}\|u\| .
\end{aligned}
$$


On the other hand, we have

$$
\begin{aligned}
\|u\|_{1, p} & =\left(\int_{0}^{1}\left[r(t)\left|u^{\prime}(t)\right|^{p}+s(t)|u(t)|^{p}\right] d t\right)^{\frac{1}{p}} \\
& \leq 2^{\frac{1}{p}-1}\left[\left[\int_{0}^{1} r(t)\left|u^{\prime}(t)\right|^{p} d t\right]^{\frac{1}{p}}+\left[\int_{0}^{1} s(t)|u(t)|^{p} d t\right]^{\frac{1}{p}}\right] \\
& \leq 2^{\frac{1}{p}-1}\left[\|r\|_{\infty}^{\frac{1}{p}}\left[\int_{0}^{1}\left|u^{\prime}(t)\right|^{p} d t\right]^{\frac{1}{p}}+\|s\|_{\infty}^{\frac{1}{p}}\left[\int_{0}^{1}\left|u^{\prime}(t)\right|^{p} d t\right]^{\frac{1}{p}}\right] \\
& \leq 2^{\frac{1}{p}-1}\left(\|r\|_{\infty}^{\frac{1}{p}}+\|s\|_{\infty}^{\frac{1}{p}}\right)\left[\int_{0}^{1}\left|u^{\prime}(t)\right|^{p} d t\right]^{\frac{1}{p}} \\
& =2^{\frac{1}{p}-1}\left(\|r\|_{\infty}^{\frac{1}{p}}+\|s\|_{\infty}^{\frac{1}{p}}\right)\|u\| .
\end{aligned}
$$

For $u \in W_{0}^{1, p}([0,1])$, it follows from the mean value theorem that

$$
u(\zeta)=\int_{0}^{1} u(\tau) d \tau
$$

for some $\zeta \in[0,1]$. Hence, for $t \in[0,1]$, using Hölder's inequality with $\frac{1}{p}+\frac{1}{q}=1$

$$
\begin{aligned}
& |u(t)|=\left|u(\zeta)+\int_{\zeta}^{t} u^{\prime}(\tau) d \tau\right| \leq \int_{0}^{1}\left|u(\tau) \tau+\int_{0}^{1}\right| u^{\prime}(\tau) \mid d \tau \\
& \leq\left(\int_{0}^{1}|u(\tau)|^{p} d \tau\right)^{\frac{1}{p}}+\left(\int_{0}^{1}\left|u^{\prime}(\tau)\right|^{p} d \tau\right)^{\frac{1}{p}} \\
& \leq \frac{1}{(e s s \inf s(t))^{\frac{1}{p}}}\left(\int_{0}^{1} s(\tau)|u(\tau)|^{p} d \tau\right)^{\frac{1}{p}} \\
& +\frac{1}{\underset{c}{(e s s \inf r(t))^{\frac{1}{p}}}}\left(\int_{0}^{1} r(\tau)\left|u^{\prime}(\tau)\right|^{p} d \tau\right)^{\frac{1}{p}}
\end{aligned}
$$

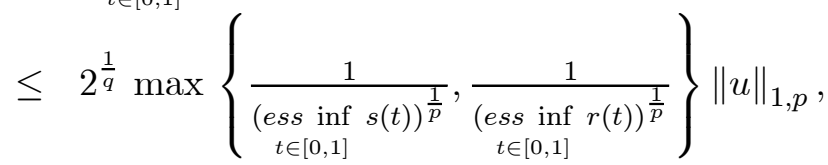

which completes the proof.

Theorem 2.1. ([25]) Suppose $V$ is a reflexive Banach space with the norm $\|.\|_{V}$ and let $M \subset V$ be a weakly closed subset of $V$. Suppose $E: M \longrightarrow$ $\mathbf{R} \cup\{+\infty\}$ is coercive and (sequentially) weakly lower semi-continuous on $M$ with respect to $V$, that is, suppose the following conditions are fulfilled 
(1) $E(u) \longrightarrow \infty$ as $\|u\|_{V} \longrightarrow \infty, u \in M$.

(2) For any $u \in M$, any sequence $\left\{u_{n}\right\}$ in $M$ such that $u_{n} \rightarrow u$ weakly in $V$ there holds

$$
E(u) \leq \liminf _{n \longrightarrow \infty} E\left(u_{n}\right) .
$$

Then, $E$ is bounded from below on $M$ and is attained its infimum in $M$.

\section{Main results}

Let $\Omega_{1}=\left\{u \in W_{0}^{1, p}([0,1]): \int_{0}^{1} m(t)|u(t)|^{p} d t=1\right\}$ and $F(u)=\int_{0}^{1}\left[r(t)\left|u^{\prime}(t)\right|^{p}+s(t)|u(t)|^{p}\right] d t+\sum_{k=1}^{i} a_{k}\left|u\left(t_{k}\right)\right|^{p}$.

In what follows, we assume that $\sum_{k=1}^{i} a_{k}^{-}<2^{p} \delta$, where $a_{k}^{-}=\max \left\{-a_{k}, 0\right\}$ for $a_{k} \in \mathbf{R}$.

Theorem 3.1. There exists a function $u_{1} \in W_{0}^{1, p}([0,1])$ such that $F\left(u_{1}\right)=$ $\inf _{u \in \Omega_{1}} F(u)=\lambda_{1}$ and $\lambda=\lambda_{1}$ is the minimal eigenvalue of (1.10) - (1.12).

Proof. For all $u \in W_{0}^{1, p}([0,1])$, by Lemma 2.3, we have

$$
\begin{aligned}
F(u) & =\int_{0}^{1}\left[r(t)\left|u^{\prime}(t)\right|^{p}+s(t)|u(t)|^{p}\right] d t+\sum_{k=1}^{i} a_{k}\left|u\left(t_{k}\right)\right|^{p} \\
& \geq \int_{0}^{1} r(t)\left|u^{\prime}(t)\right|^{p} d t+\sum_{k=1}^{i} a_{k}\left|u\left(t_{k}\right)\right|^{p} \\
& \geq \delta\|u\|^{p}+\sum_{k=1}^{i} a_{k}\left|u\left(t_{k}\right)\right|^{p} \\
& \geq\left(\delta-\frac{1}{2^{p}} \sum_{k=1}^{i} a_{k}^{-}\right)\|u\|^{p}=c_{0}\|u\|^{p} .
\end{aligned}
$$

Let $\left\{u_{n}\right\}_{n \in \mathbf{N}}$ be a minimizing sequence on $\Omega_{1}$ such that $F\left(u_{n}\right) \longrightarrow \lambda_{1}$ as $n \longrightarrow+\infty$. Hence, the above inequality implies that there exists $c_{0}>0$ such that $F\left(u_{n}\right) \geq c_{0}\left\|u_{n}\right\|^{p}$. Therefore, the sequence $\left\{u_{n}\right\}_{n \in \mathbf{N}}$ is bounded. Since $W_{0}^{1, p}([0,1])$ is a reflexive Banach space, up to a subsequence, still denoted by $\left\{u_{n}\right\}$ such that $u_{n} \rightarrow u$ in $W_{0}^{1, p}([0,1])$ and

$$
u_{n} \longrightarrow u \text { in } L^{p}([0,1]) \text {, }
$$




$$
u_{n}(t) \longrightarrow u(t) \text { a.e } t \in[0,1] .
$$

Notice that

$$
\begin{aligned}
F(u) & =\int_{0}^{1}\left[r(t)\left|u^{\prime}(t)\right|^{p}+s(t)|u(t)|^{p}\right] d t+\sum_{k=1}^{i} a_{k}\left|u\left(t_{k}\right)\right|^{p} \\
& =\|u\|_{1, p}^{p}+\sum_{k=1}^{i} a_{k}\left|u\left(t_{k}\right)\right|^{p} \\
& \leq \liminf _{n \rightarrow+\infty}\left\|u_{n}\right\|_{1, p}^{p}+\liminf _{n \rightarrow+\infty} \sum_{k=1}^{i} a_{k}\left|u_{n}\left(t_{k}\right)\right|^{p} \\
& =\liminf _{n \rightarrow+\infty}\left(\left\|u_{n}\right\|_{1, p}^{p}+\sum_{k=1}^{i} a_{k}\left|u_{n}\left(t_{k}\right)\right|^{p}\right) \\
& =\liminf _{n \rightarrow+\infty} F\left(u_{n}\right)=\lambda_{1} .
\end{aligned}
$$

Since $u \in \Omega_{1}$, by Theorem 2.1 there exists $u_{1} \in W_{0}^{1, p}([0,1])$ such that $F\left(u_{1}\right)=\inf _{u \in \Omega_{1}} F(u)=\lambda_{1}$.

It remains to show that $u_{1}$ is a solution of $(1.10)-(1.12)$, we have

$$
\lambda_{1}=\inf _{\substack{u \in W_{0}^{1, p}([0,1]) \\ u \neq 0}} \frac{F(u)}{\int_{0}^{1} m(t)|u(t)|^{p} d t},
$$

let $u \in W_{0}^{1, p}([0,1])$, and consider the function

$$
\varphi(s)=\frac{F\left(u_{1}(t)+s u(t)\right)}{\int_{0}^{1} m(t)\left|u_{1}(t)+s u(t)\right|^{p} d t} .
$$

We set $\varphi_{1}(s)=F\left(u_{1}(t)+s u(t)\right)$ and $\varphi_{2}(s)=\int_{0}^{1} m(t)\left|u_{1}(t)+s u(t)\right|^{p} d t$.

By (3.1), we have $\varphi(s) \geq \varphi(0)=\lambda_{1}$ which implies that $\varphi_{1}(s) \geq \lambda_{1} \varphi_{2}(s)$ for all $s \in \mathbf{R}$. Next, by applying Taylor's formula for $\varphi_{1}$ and $\varphi_{2}$, we get

$$
\begin{gathered}
\varphi_{1}(s)=F\left(u_{1}(t)\right)+s p\left[\int_{0}^{1} r(t)\left|u_{1}^{\prime}(t)\right|^{p-2} u_{1}^{\prime}(t) u^{\prime}(t) d t\right. \\
\left.+\int_{0}^{1} s(t)\left|u_{1}(t)\right|^{p-2} u_{1}(t) u(t) d t\right]+s p \sum_{k=1}^{i} a_{k}\left|u_{1}\left(t_{k}\right)\right|^{p-2} u_{1}\left(t_{k}\right) u\left(t_{k}\right)+\frac{s^{2} \varphi_{1}^{(2)}(0)}{2}+O\left(s^{2}\right),
\end{gathered}
$$


and

$\varphi_{2}(s)=\int_{0}^{1} m(t)\left|u_{1}(t)\right|^{p} d t+p s \int_{0}^{1} m(t)\left|u_{1}(t)\right|^{p-2} u_{1}(t) u(t) d t+\frac{s^{2} \varphi_{2}^{(2)}(0)}{2}+O\left(s^{2}\right)$.

As $\varphi_{1}(0)=F\left(u_{1}\right)=\lambda_{1}$ and $\varphi_{2}(0)=\int_{0}^{1} m(t)\left|u_{1}(t)\right|^{p} d t=1$. Then, for $s>0$, we have

$$
\varphi_{1}(s)-\varphi_{1}(0) \geq \lambda_{1} \varphi_{2}(s)-\varphi_{1}(0)=\lambda_{1}\left(\varphi_{2}(s)-\varphi_{2}(0)\right),
$$

which implies that

$$
\frac{\varphi_{1}(s)-\varphi_{1}(0)}{s} \geq \lambda_{1} \frac{\varphi_{2}(s)-\varphi_{2}(0)}{s},
$$

by passing to the limit when $s \longrightarrow 0^{+}$, we obtain $\varphi_{1}^{\prime}(0) \geq \lambda_{1} \varphi_{2}^{\prime}(0)$.

Similarly, in the case where $s<0$, we have $\varphi_{1}^{\prime}(0) \leq \lambda_{1} \varphi_{2}^{\prime}(0)$. Thus, for all $s \in \mathbf{R}$, we get

$$
\varphi_{1}^{\prime}(0)=\lambda_{1} \varphi_{2}^{\prime}(0) .
$$

From (3.2) it follows that

$$
\begin{aligned}
& \int_{0}^{1} r(t)\left|u_{1}^{\prime}(t)\right|^{p-2} u_{1}^{\prime}(t) u^{\prime}(t) d t+\int_{0}^{1} s(t)\left|u_{1}(t)\right|^{p-2} u_{1}(t) u(t) d t \\
& \quad+\sum_{k=1}^{i} a_{k}\left|u_{1}\left(t_{k}\right)\right|^{p-2} u_{1}\left(t_{k}\right) u\left(t_{k}\right)=\lambda_{1} \int_{0}^{1} m(t)\left|u_{1}(t)\right|^{p-2} u_{1}(t) u(t) d t .
\end{aligned}
$$

For $k \in\{0,1, \ldots, i\}$, choose $u \in W_{0}^{1, p}([0,1])$ with $u(t)=0$ for all $t \in\left[0, t_{k}\right] \cup\left[t_{k+1}, 1\right]$, then

$$
\begin{gathered}
\int_{t_{k}}^{t_{k+1}} r(t)\left|u_{1}^{\prime}(t)\right|^{p-2} u_{1}^{\prime}(t) u^{\prime}(t) d t+\int_{t_{k}}^{t_{k+1}} s(t)\left|u_{1}(t)\right|^{p-2} u_{1}(t) u(t) d t \\
=\lambda_{1} \int_{t_{k}}^{t_{k+1}} m(t)\left|u_{1}(t)\right|^{p-2} u_{1}(t) u(t) d t
\end{gathered}
$$

which implies that

(3.4) $-\left(r(t)\left|u_{1}^{\prime}(t)\right|^{p-2} u_{1}^{\prime}(t)\right)^{\prime}+s(t)\left|u_{1}(t)\right|^{p-2} u_{1}(t)=\lambda_{1} m(t)\left|u_{1}(t)\right|^{p-2} u_{1}(t)$ 
a.e. on $t \in] t_{k}, t_{k+1}\left[\right.$. Hence, $u_{1} \in W^{2, p}(] t_{k}, t_{k+1}[)$ and $u_{1}$ satisfy (1.1) a.e. on $[0,1]$.

Now, multiplying the above equation by $u \in W_{0}^{1, p}([0,1])$ and integrating between 0 to 1 , we get

$$
\begin{aligned}
& \int_{0}^{1} r(t)\left|u_{1}^{\prime}(t)\right|^{p-2} u_{1}^{\prime}(t) u^{\prime}(t) d t+\int_{0}^{1} s(t)\left|u_{1}(t)\right|^{p-2} u_{1}(t) u(t) d t \\
& \quad+\sum_{k=1}^{i} u\left(t_{k}\right) \Delta_{p} u_{1}^{\prime}\left(t_{k}\right)=\lambda_{1} \int_{0}^{1} m(t)\left|u_{1}(t)\right|^{p-2} u_{1}(t) u(t) d t .
\end{aligned}
$$

Combining (3.3) with (3.5), we have

$$
\sum_{k=1}^{i} u\left(t_{k}\right) \Delta_{p} u_{1}^{\prime}\left(t_{k}\right)=\sum_{k=1}^{i} a_{k}\left|u_{1}\left(t_{k}\right)\right|^{p-2} u_{1}\left(t_{k}\right) u\left(t_{k}\right) .
$$

Hence, $\Delta_{p} u_{1}^{\prime}\left(t_{k}\right)=a_{k}\left|u_{1}\left(t_{k}\right)\right|^{p-2} u_{1}\left(t_{k}\right)$, for all $k \in\{1,2, \ldots, i\}$. This means that $u_{1}$ is a solution of $(1.10)-(1.12)$.

Corollary 3.1.1. Let $u_{1} \in \Omega_{1}$ such that $F\left(u_{1}\right)=\inf _{u \in \Omega_{1}} F(u)$, then $u_{1}$ is either positive or negative in $] 0,1[$.

Proof. Let $u_{1} \in \Omega_{1}$ be an eigenfunction that corresponds to the first eigenvalue $\lambda_{1}$. Then, $u_{1}$ satisfies the following equations

$\int_{0}^{1} m(t)\left|u_{1}(t)\right|^{p} d t=1, \int_{0}^{1}\left[r(t)\left|u_{1}^{\prime}(t)\right|^{p}+s(t)\left|u_{1}(t)\right|^{p}\right] d t+\sum_{k=1}^{i} a_{k}\left|u_{1}\left(t_{k}\right)\right|^{p}=\lambda_{1}$.

The eigenfunction $y=\left|u_{1}\right|$ satisfies the above equations. Hence, $y$ is also a solution of $(1.10)-(1.12)$ with $\lambda=\lambda_{1}$. By Lemma 2.2 there exists $c \neq 0$ such this $u_{1}=c y$ or $y=c u_{1}$. Hence, $u_{1}$ does not change its sign. Let's assume that $u_{1} \geq 0$ then $u_{1}>0$ because if there exists $\left.x_{0} \in\right] 0,1[$ such that $u_{1}\left(x_{0}\right)=0$, by Harnack's inequality for all positive eigenfunction, we have

$$
\max _{B_{\varepsilon}} u_{1} \leq C_{p} \min _{B_{\varepsilon}} u_{1}
$$

with $\left.B_{\varepsilon}=B\left(x_{0}, \varepsilon\right)=\right] x_{0}-\varepsilon, x_{0}+\varepsilon\left[\right.$ and $B\left(x_{0}, 2 \varepsilon\right) \subset[0,1]$. It follows that $u_{1} \equiv 0$ on $B_{\varepsilon}$ for all $\varepsilon>0$. In conclusion, $u_{1} \equiv 0$ which is impossible, because $u_{1}$ is an eigenfunction. Therefore, $\left|u_{1}\right|>0$ on $[0,1]$. Thus, $u_{1}$ is of constant sign. 
Proposition 3.1. The first eigenvalue $\lambda_{1}$ is simple, i.e., if $u$ and $v$ are two eigenfunctions associated with $\lambda_{1}$, then there exists a constant $c$ such that $u=c v$.

Proof. $\quad$ See lemma 2.2.

Theorem 3.2. ([26]) Let $v>0, u \geq 0$ be functions on an interval $\Omega$ and differentiable a.e. on $\Omega$. Denote

$$
\begin{gathered}
L(u, v)=\left|u^{\prime}\right|^{p}+(p-1) \frac{u^{p}}{v^{p}}\left|v^{\prime}\right|^{p}-p \frac{u^{p-1}}{v^{p-1}}\left|v^{\prime}\right|^{p-2} v^{\prime} u^{\prime} \\
R(u, v)=\left|u^{\prime}\right|^{p}+\left|v^{\prime}\right|^{p-2} v^{\prime}\left(\frac{u^{p}}{v^{p-1}}\right)^{\prime} .
\end{gathered}
$$

Then, we have

(1) $L(u, v)=R(u, v)$.

(2) $L(u, v) \geq 0$ a.e. on $\Omega$.

(3) $L(u, v)=0$ a.e. on $\Omega$ if and only if $u=\xi v$ for some $\xi \in \mathbf{R}$.

Proposition 3.2. Let $u$ be an eigenfunction which corresponds to $\lambda \neq \lambda_{1}$. Then, $u$ changes sign on $J=[0,1]$.

Proof. Assume by contradiction that $u \geq 0$. By strong maximum principle, it follows that $u(t)>0$ for all $t \in[0,1]$. Let $u_{1}>0$ be an eigenfunction associated to $\lambda_{1}$. For any $\varepsilon>0$, we apply the Picone's identity to the pair $\left(u_{1}(t), u(t)+\varepsilon\right)$. Then, we have

$$
\int_{0}^{1} r(t) L\left(u_{1}(t), u(t)+\varepsilon\right) d t=\int_{0}^{1} r(t) R\left(u_{1}(t), u(t)+\varepsilon\right) d t \geq 0,
$$

and

$$
\begin{gathered}
\int_{0}^{1} r(t) R\left(u_{1}(t), u(t)+\varepsilon\right) d t=\int_{0}^{1} r(t)\left|u_{1}^{\prime}(t)\right|^{p} d t \\
-\int_{0}^{1} r(t)\left|u^{\prime}(t)\right|^{p-2} u^{\prime}(t)\left(\frac{u_{1}^{p}(t)}{(u(t)+\varepsilon)^{p-1}}\right)^{\prime} d t
\end{gathered}
$$

where

$$
\int_{0}^{1} r(t)\left|u_{1}^{\prime}(t)\right|^{p} d t=\lambda_{1} \int_{0}^{1} m(t)\left|u_{1}(t)\right|^{p} d t-\int_{0}^{1} s(t)\left|u_{1}(t)\right|^{p} d t
$$




$$
-\sum_{k=1}^{i} a_{k}\left|u_{1}\left(t_{k}\right)\right|^{p}
$$

also

$$
\begin{aligned}
& \int_{0}^{1} r(t)\left|u^{\prime}(t)\right|^{p-2} u^{\prime}(t)\left(\frac{u_{1}^{p}(t)}{(u(t)+\varepsilon)^{p-1}}\right)^{\prime} d t \\
= & \lambda \int_{0}^{1} m(t)|u(t)|^{p-2} u(t)\left(\frac{u_{1}^{p}(t)}{(u(t)+\varepsilon)^{p-1}}\right) d t \\
& -\int_{0}^{1} s(t)|u(t)|^{p-2} u(t)\left(\frac{u_{1}^{p}(t)}{(u(t)+\varepsilon)^{p-1}}\right) d t \\
& -\sum_{k=1}^{i} a_{k}\left|u\left(t_{k}\right)\right|^{p-2} u\left(t_{k}\right)\left(\frac{u_{1}^{p}\left(t_{k}\right)}{\left(u\left(t_{k}\right)+\varepsilon\right)^{p-1}}\right) .
\end{aligned}
$$

Combining (3.6) with (3.7), we have

$$
\begin{gathered}
\int_{0}^{1} r(t) R\left(u_{1}(t), u(t)+\varepsilon\right) d t \\
=\int_{0}^{1} m(t)\left(\lambda_{1}\left|u_{1}(t)\right|^{p}-\lambda|u(t)|^{p-2} u(t) \frac{u_{1}^{p}(t)}{(u(t)+\varepsilon)^{p-1}}\right) d t \\
+\int_{0}^{1} s(t)\left(|u(t)|^{p-2} u(t) \frac{u_{1}^{p}(t)}{(u(t)+\varepsilon)^{p-1}}-\left|u_{1}(t)\right|^{p}\right) d t \\
+\sum_{k=1}^{i} a_{k}\left(\left|u\left(t_{k}\right)\right|^{p-2} u\left(t_{k}\right) \frac{u_{1}^{p}\left(t_{k}\right)}{\left(u\left(t_{k}\right)+\varepsilon\right)^{p-1}}-\left|u_{1}\left(t_{k}\right)\right|^{p}\right) .
\end{gathered}
$$

Tending $\varepsilon$ tend towards 0 in (3.8), we obtain

$$
\int_{0}^{1} m(t)\left(\lambda_{1}-\lambda\right)\left|u_{1}(t)\right|^{p} d t \geq 0
$$

Since $\lambda>\lambda_{1}$ and $\int_{0}^{1} m(t)\left|u_{1}(t)\right|^{p} d t>0$, we get a contradiction. Therefore, $u$ changes sign in $[0,1]$. 


\subsection{The Ljusternik-Schnirelman principle}

Let $W_{0}^{1, p}([0,1])$ be a real reflexive Banach space and $F, G$ be two functionals on $W_{0}^{1, p}([0,1])$. Consider the following eigenvalue problem

$$
G^{\prime}(u)=\mu F^{\prime}(u), u \in S_{F}, \mu \in \mathbf{R} .
$$

where $S_{F}=\left\{u \in W_{0}^{1, p}([0,1]): F(u)=1\right\}$. We assume that

$\left(H_{1}\right) F, G: W_{0}^{1, p}([0,1]) \longrightarrow \mathbf{R}$ are even functionals and that $F, G \in C^{1}\left(W_{0}^{1, p}([0,1]), \mathbf{R}\right)$ with $F(0)=G(0)=0$.

$\left(H_{2}\right) G^{\prime}$ is strongly continuous (i.e. $u_{n} \rightarrow u$ in $W_{0}^{1, p}([0,1])$ implies $G^{\prime}\left(u_{n}\right) \longrightarrow$ $\left.G^{\prime}(u)\right)$ and $\left\langle G^{\prime}(u), u\right\rangle=0, u \in \overline{c o S_{F}}$ implies $G(u)=0$, where $\overline{c o S_{F}}$ is the closed convex hull of $S_{F}$.

$\left(H_{3}\right) F^{\prime}$ is continuous, bounded, and satisfies condition $\left(S_{0}\right)$, i.e. as $n \longrightarrow$ $+\infty$

$$
u_{n} \rightarrow u, F^{\prime}\left(u_{n}\right) \rightarrow v,\left\langle F^{\prime}\left(u_{n}\right), u_{n}\right\rangle \longrightarrow\langle v, u\rangle \text { implies } u_{n} \longrightarrow u .
$$

$\left(H_{4}\right)$ The set $S_{F}$ is bounded and $u \neq 0$ implies

$$
\left\langle F^{\prime}(u), u\right\rangle>0, \lim _{t \longrightarrow \infty} F(t u)=+\infty, \inf _{u \in S_{F}}\left\langle F^{\prime}(u), u\right\rangle>0 .
$$

It is known that $(u, \mu)$ solves (3.10) if and only if $u$ is a critical point of $G$ with respect to $S_{F}$.

For any positive integer $n$, denoted by $\mathcal{C}_{n}$ the class of all compact, symmetric subsets $K$ of $S_{F}$ such that $G(u)>0$ on $K$ and $\gamma(K) \geq n$, where $\gamma(K)$ denotes the genus of $K$, i.e., $\gamma(K)=\inf \{k \in \mathbf{N}: \exists h: K \longrightarrow$ $\mathbf{R}^{k} \backslash\{0\}$ such that $h$ is continuous and odd $\}$. Let

$b_{n}=\left\{\begin{array}{ll}\sup _{H \in \mathcal{C}_{n}} \inf _{u \in H} G(u), & \mathcal{C}_{n} \neq \emptyset, \\ 0 & \mathcal{C}_{n}=\emptyset\end{array}\right.$ and $\chi= \begin{cases}\sup \left\{n \in \mathbf{N}: b_{n}>0\right\} & \text { if } b_{1}>0, \\ 0 & \text { if } b_{1}=0 .\end{cases}$

Lemma 3.1. ([27]) Let $\Omega$ be a domain in $\mathbf{R}$ and let $\Phi: \mathbf{R}^{+} \longrightarrow \mathbf{R}^{+}$be a Young function which satisfies a $\Delta_{2}$-condition, i.e., there is $c>0$ such that 
$\Phi(2 t) \leq c \Phi(t)$ for all $t \geq 0$. If $\left\{u_{n}\right\}$ be a sequence of integrable functions on $[0,1]$, such that

$\lim _{n \longrightarrow+\infty} u_{n}(t)=u(t)$, a.e. $t \in[0,1]$ and $\int_{0}^{1} \Phi(|u(t)|) d t=\lim _{n \longrightarrow+\infty} \int_{0}^{1} \Phi\left(\left|u_{n}(t)\right|\right) d t$,

then

$$
\lim _{n \longrightarrow+\infty} \int_{0}^{1} \Phi\left(\left|u_{n}(t)-u(t)\right|\right) d t=0
$$

Theorem 3.3. ([28]) Under the assumptions $\left(H_{1}\right)-\left(H_{4}\right)$, the following assertions hold:

(1) If $b_{n}>0$, then (3.10) possesses a pair $\left(-u_{n},+u_{n}\right)$ of eigenfunctions and eigenvalues $\mu_{n} \neq 0$. Furthermore, $G\left(u_{n}\right)=b_{n}$.

(2) If $\chi=\infty,(3.10)$ has infinitely many pairs $(-u,+u)$ of eigenfunctions which correspond to nonzero eigenvalues.

(3) $\infty>b_{1} \geq b_{2} \geq \cdots \geq 0$ and $b_{n} \longrightarrow 0$ as $n \longrightarrow+\infty$.

(4) If $\chi=\infty$ and $G(u)=0, u \in \overline{c o S_{F}}\left(c o S_{F}\right.$ is a convex envelope of $\left.S_{F}\right)$ implies $\langle G(u), u\rangle=0$, then there exists an infinite sequence $\left\{\mu_{n}\right\}$ of distinct eigenvalues of (3.10) such that $\mu_{n} \longrightarrow 0$ as $n \longrightarrow+\infty$.

(5) Assume that $G(u)=0, u \in \overline{\operatorname{coS}_{F}}$ implies $u=0$. Then $\chi=\infty$ and there exists a sequence of eigenpairs $\left\{\left(u_{n}, \mu_{n}\right)\right\}$ of (3.10) such that $u_{n} \rightarrow 0, \mu_{n} \longrightarrow 0$ as $n \longrightarrow+\infty$ and $\mu_{n} \neq 0$ for all $n$.

Proof. For the proof, we can see [25] or [29]. tionals

We define on $W_{0}^{1, p}([0,1])$ the norm $\|\cdot\|_{1, p}$ and let be the following func-

$$
G(u)=\int_{0}^{1} m(t)|u(t)|^{p} d t \text { and } F(u)=\int_{0}^{1}\left[r(t)\left|u^{\prime}(t)\right|^{p}+s(t)|u(t)|^{p}\right] d t
$$

$$
+\sum_{k=1}^{i} a_{k}\left|u\left(t_{k}\right)\right|^{p},
$$

as before, we define $S_{F}=\left\{u \in W_{0}^{1, p}([0,1]): F(u)=1\right\}$. The functionals $F$ and $G$ are the class $C^{1}([0,1])$. 

have

Let $A=\frac{1}{p} G^{\prime}, B=\frac{1}{p} F^{\prime}$ and $a_{k} \in \mathbf{R}$. Then for all $u, v \in W_{0}^{1, p}([0,1])$, we

$$
\langle A(u), v\rangle=\int_{0}^{1} m(t)|u(t)|^{p-2} u(t) v(t) d t
$$

and

$$
\begin{gathered}
\langle B(u), v\rangle=\int_{0}^{1}\left[r(t)\left|u^{\prime}(t)\right|^{p-2} u^{\prime}(t) v^{\prime}(t)+s(t)|u(t)|^{p-2} u(t) v(t)\right] d t \\
+\sum_{k=1}^{i} a_{k}\left|u\left(t_{k}\right)\right|^{p-2} u\left(t_{k}\right) v\left(t_{k}\right),
\end{gathered}
$$

We consider the eigenvalue problem $A u=\mu B u$, where $\mu \in \mathbf{R}$ and $F(u)=1$. Thus for any $v \in W_{0}^{1, p}([0,1])$,

$$
\begin{aligned}
& \int_{0}^{1} m(t)|u(t)|^{p-2} u(t) v(t) d t \\
& =\mu\left(\int_{0}^{1}\left[r(t)\left|u^{\prime}(t)\right|^{p-2} u^{\prime}(t) v^{\prime}(t)+s(t)|u(t)|^{p-2} u(t) v(t)\right] d t\right. \\
& +\sum_{k=1}^{i} a_{k}\left|u\left(t_{k}\right)\right|^{p-2} u\left(t_{k}\right) v\left(t_{k}\right) .
\end{aligned}
$$

We claim that $F$ and $G$ satisfy the already mentioned hypotheses $\left(H_{1}\right)$ $\left(H_{4}\right)$.

Proposition 3.3. Let $G$ be defined in (3.12), then $G^{\prime}$ satisfies $\left(H_{2}\right)$.

Proof. We show that $A$ is strongly continuous. Let $u_{n} \rightarrow u$ in $W_{0}^{1, p}([0,1])$, we want to show that $A u_{n} \longrightarrow A u$ in $\left(W_{0}^{1, p}([0,1])\right)^{*}$. For any $v \in W_{0}^{1, p}([0,1])$, by Hölder's inequality, it follows that

$$
\begin{aligned}
\left|\left\langle A u_{n}-A u, v\right\rangle\right| & \leq\left|\int_{0}^{1} m(t)\left(\left|u_{n}(t)\right|^{p-2} u_{n}(t)-|u(t)|^{p-2} u(t)\right) v(t) d t\right| \\
& \leq\left.\|m\|_{\infty} \int_{0}^{1}|| u_{n}(t)\right|^{p-2} u_{n}(t)-|u(t)|^{p-2} u(t)|| v(t) \mid d t \\
& \leq\|m\|_{\infty}\left\|\left.u_{n}\right|^{p-2} u_{n}-|u|^{p-2} u\right\|_{L^{\frac{p}{p-1}}}\|v\|_{L^{p}},
\end{aligned}
$$

where $\|m\|_{\infty}=\max _{t \in[0,1]} m(t)$ 
Next, we show that $\left|u_{n}\right|^{p-2} u_{n} \longrightarrow|u|^{p-2} u$ in $L^{\frac{p}{p-1}}([0,1])$. To check that, let $w_{n}=\left|u_{n}\right|^{p-2} u_{n}$ and $w=|u|^{p-2} u$. Since $u_{n} \rightarrow u \in W_{0}^{1, p}([0,1]), u_{n} \longrightarrow$ $u \in L^{p}([0,1])$, it follows that

$$
w_{n}(t) \longrightarrow w(t), \text { a.e.in }[0,1] \text { and } \int_{0}^{1}\left|w_{n}(t)\right|^{\frac{p}{p-1}} d t \longrightarrow \int_{0}^{1}|w(t)|^{\frac{p}{p-1}} d t .
$$

By Lemma 3.1, we deduce that $w_{n} \longrightarrow w$ in $L^{\frac{p}{p-1}}([0,1])$, which implies that $A u_{n} \longrightarrow A u$ in $\left(W_{0}^{1, p}([0,1])\right)^{*}$.

Proposition 3.4. Let $B$ be defined in (3.14). Then for any $u, v \in W_{0}^{1, p}([0,1])$, one has

$$
\begin{gathered}
\langle B u-B v, u-v\rangle \geq\left(\|u\|_{1, p}^{p}-\|v\|_{1, p}^{p}\right)\left(\|u\|_{1, p}-\|v\|_{1, p}\right) \\
+\sum_{k=1}^{i} a_{k}\left(\left|u\left(t_{k}\right)\right|^{p-1}-\left|v\left(t_{k}\right)\right|^{p-1}\right)\left(\left|u\left(t_{k}\right)\right|-\left|v\left(t_{k}\right)\right|\right) .
\end{gathered}
$$

Proof. Through technical calculations, we have

$$
\begin{aligned}
\langle B u-B v, u-v\rangle & =\int_{0}^{1} r(t)\left[\left|u^{\prime}(t)\right|^{p}+\left|v^{\prime}(t)\right|^{p}-\left|u^{\prime}(t)\right|^{p-2} u^{\prime}(t) v^{\prime}(t)\right. \\
& \left.-\left|v^{\prime}(t)\right|^{p-2} v^{\prime}(t) u^{\prime}(t)\right] d t \\
& +\int_{0}^{1} s(t)\left[|u(t)|^{p}+|v(t)|^{p}-|u(t)|^{p-2} u(t) v(t)\right. \\
& \left.-|v(t)|^{p-2} v(t) u(t)\right] d t \\
& +\sum_{k=1}^{i} a_{k}\left[\left|u\left(t_{k}\right)\right|^{p}+\left|v\left(t_{k}\right)\right|^{p}-\left|u\left(t_{k}\right)\right|^{p-2} u\left(t_{k}\right) v\left(t_{k}\right)\right. \\
& \left.-\left|v\left(t_{k}\right)\right|^{p-2} v\left(t_{k}\right) u\left(t_{k}\right)\right] .
\end{aligned}
$$

Since

$$
\begin{aligned}
& \sum_{k=1}^{i} a_{k}\left[\left|u\left(t_{k}\right)\right|^{p}+\left|v\left(t_{k}\right)\right|^{p}-\left|u\left(t_{k}\right)\right|^{p-2} u\left(t_{k}\right) v\left(t_{k}\right)-\left|v\left(t_{k}\right)\right|^{p-2} v\left(t_{k}\right) u\left(t_{k}\right)\right] \\
\geq & \sum_{k=1}^{i} a_{k}\left[\left|u\left(t_{k}\right)\right|^{p}+\left|v\left(t_{k}\right)\right|^{p}-\left|u\left(t_{k}\right)\right|^{p-1} v\left(t_{k}\right)-\left|v\left(t_{k}\right)\right|^{p-1} u\left(t_{k}\right)\right] \\
\geq & \sum_{k=1}^{i} a_{k}\left(\left|u\left(t_{k}\right)\right|^{p-1}-\left|v\left(t_{k}\right)\right|^{p-1}\right)\left(\left|u\left(t_{k}\right)\right|-\left|v\left(t_{k}\right)\right|\right) .
\end{aligned}
$$


Therefore

$$
\begin{aligned}
& \langle B u-B v, u-v\rangle \\
\geq & \int_{0}^{1} r(t)\left[\left|u^{\prime}(t)\right|^{p}+\left|v^{\prime}(t)\right|^{p}-\left|u^{\prime}(t)\right|^{p-2} u^{\prime}(t) v^{\prime}(t)-\left|v^{\prime}(t)\right|^{p-2} v^{\prime}(t) u^{\prime}(t)\right] d t \\
+ & \int_{0}^{1} s(t)\left[|u(t)|^{p}+|v(t)|^{p}-|u(t)|^{p-2} u(t) v(t)-|v(t)|^{p-2} v(t) u(t)\right] d t \\
= & \|u\|_{1, p}^{p}+\|v\|_{1, p}^{p}-\int_{0}^{1}\left[r(t)\left|u^{\prime}(t)\right|^{p-2} u^{\prime}(t) v^{\prime}(t)+s(t)|u(t)|^{p-2} u(t) v(t)\right] d t \\
- & \int_{0}^{1}\left[r(t)\left|v^{\prime}(t)\right|^{p-2} v^{\prime}(t) u^{\prime}(t)+s(t)|v(t)|^{p-2} v(t) u(t)\right] d t .
\end{aligned}
$$

By Hölder's inequality, we get

$$
\begin{gathered}
\int_{0}^{1}\left[r(t)\left|u^{\prime}(t)\right|^{p-2} u^{\prime}(t) v^{\prime}(t)+s(t)|u(t)|^{p-2} u(t) v(t)\right] d t \\
\leq\left(\int_{0}^{1} r(t)\left|u^{\prime}(t)\right|^{p} d t\right)^{\frac{p-1}{p}}\left(\int_{0}^{1} r(t)\left|v^{\prime}(t)\right|^{p} d t\right)^{\frac{1}{p}} \\
\quad+\left(\int_{0}^{1} s(t)|u(t)|^{p} d t\right)^{\frac{p-1}{p}}\left(\int_{0}^{1} s(t)|v(t)|^{p} d t\right)^{\frac{1}{p}} .
\end{gathered}
$$

Using the following inequality

$$
(a+b)^{\zeta}(c+d)^{1-\zeta} \geq a^{\zeta} c^{1-\zeta}+b^{\zeta} d^{1-\zeta},
$$

which holds for any $\zeta \in] 0,1\left[\right.$ and $a>0, b>0, c>0, d>0$. Set $\zeta=\frac{p-1}{p}$ and

$$
\begin{aligned}
& a=\int_{0}^{1} r(t)\left|u^{\prime}(t)\right|^{p} d t, b=\int_{0}^{1} s(t)|u(t)|^{p} d t, \\
& c=\int_{0}^{1} r(t)\left|v^{\prime}(t)\right|^{p} d t, d=\int_{0}^{1} s(t)|v(t)|^{p} d t .
\end{aligned}
$$

Then, we can deduce that

$$
\int_{0}^{1}\left[r(t)\left|u^{\prime}(t)\right|^{p-2} u^{\prime}(t) v^{\prime}(t)+s(t)|u(t)|^{p-2} u(t) v(t)\right] d t \leq\|u\|_{1, p}^{p-1}\|v\|_{1, p},
$$

and

$$
\int_{0}^{1}\left[r(t)\left|v^{\prime}(t)\right|^{p-2} v^{\prime}(t) u^{\prime}(t)+s(t)|v(t)|^{p-2} v(t) u(t)\right] d t \leq\|v\|_{1, p}^{p-1}\|u\|_{1, p} .
$$


Therefore, we have

$$
\begin{gathered}
\langle B u-B v, u-v\rangle \geq\|u\|_{1, p}^{p}+\|v\|_{1, p}^{p}-\|u\|_{1, p}^{p-1}\|v\|_{1, p}-\|v\|_{1, p}^{p-1}\|u\|_{1, p} \\
+\sum_{k=1}^{i} a_{k}\left(\left|u\left(t_{k}\right)\right|^{p-1}-\left|v\left(t_{k}\right)\right|^{p-1}\right)\left(\left|u\left(t_{k}\right)\right|-\left|v\left(t_{k}\right)\right|\right) \\
\geq\left(\|u\|_{1, p}^{p-1}-\|v\|_{1, p}^{p-1}\right)\left(\|u\|_{1, p}-\|v\|_{1, p}\right)+\sum_{k=1}^{i} a_{k}\left(\left|u\left(t_{k}\right)\right|^{p-1}\right. \\
\left.-\left|v\left(t_{k}\right)\right|^{p-1}\right)\left(\left|u\left(t_{k}\right)\right|-\left|v\left(t_{k}\right)\right|\right) .
\end{gathered}
$$

Proposition 3.5. The functionals $F$ and $G$ satisfy the hypotheses $\left(H_{1}\right)$ and $\left(H_{4}\right)$.

Proof. Let's show that $F^{\prime}$ and $G^{\prime}$ are continuous. Denote by $\|\cdot\|_{*}$ the norm of the dual space $W_{0}^{1, p}([0,1])$. Let $\left\{u_{n}\right\}_{n \in \mathbf{N}}$ be a sequence in $W_{0}^{1, p}([0,1])$, such that $u_{n} \longrightarrow u$ in $W_{0}^{1, p}([0,1])$

$$
\begin{aligned}
\left|\left\langle F^{\prime}\left(u_{n}\right)-F^{\prime}(u), v\right\rangle\right| \leq & \left.\int_{0}^{1} r(t)|| u_{n}^{\prime}(t)\right|^{p-2} u_{n}^{\prime}(t)-\left|u^{\prime}(t)\right|^{p-2} u^{\prime}(t) \| v^{\prime}(t) t \\
& +\left.\int_{0}^{1} s(t)|| u_{n}(t)\right|^{p-2} u_{n}(t)-|u(t)|^{p-2} u(t)|| v(t) t \\
& +\left.\sum_{k=1}^{i}\left|a_{k}\right||| u_{n}\left(t_{k}\right)\right|^{p-2} u_{n}\left(t_{k}\right)-\left|u\left(t_{k}\right)\right|^{p-2} u\left(t_{k}\right) \| v\left(t_{k}\right) \mid .
\end{aligned}
$$

By Hölder's inequality with the compact embedding of $W_{0}^{1, p}([0,1])$ in $L^{p}([0,1])$ and Lemma 2.4 , we have

$$
\begin{aligned}
& \left|\left\langle F^{\prime}\left(u_{n}\right)-F^{\prime}(u), v\right\rangle\right| \leq\|r\|_{\infty}\left\|\left|u_{n}^{\prime}\right|^{p-2} u_{n}^{\prime}-\left|u^{\prime}\right|^{p-2} u^{\prime}\right\|_{L^{\frac{p}{p-1}}}\left\|v^{\prime}\right\|_{L^{p}} \\
& +\|s\|_{\infty}\left\|\left|u_{n}\right|^{p-2} u_{n}-\left.|u|^{p-2} u\right|_{L^{\frac{p}{p-1}}}\right\| v \|_{L^{p}} \\
& +\left.\max _{k=1, \ldots, i}\left|a_{k}\right|\|v\|_{\infty} \sum_{k=1}^{i}|| u_{n}\left(t_{k}\right)\right|^{p-2} u_{n}\left(t_{k}\right)-\left|u\left(t_{k}\right)\right|^{p-2} u\left(t_{k}\right) \mid \\
& \leq\|r\|_{\infty}\left\|\left|u_{n}^{\prime}\right|^{p-2} u_{n}^{\prime}-\left|u^{\prime}\right|^{p-2} u^{\prime}\right\|_{L^{\frac{p}{p-1}}}\|v\|+c_{p}\|s\|_{\infty} \|\left|u_{n}\right|^{p-2} u_{n} \\
& -|u|^{p-2} u\left\|_{L^{\frac{p}{p-1}}}\right\| v \| \\
& +\left.c_{\infty}\|v\|_{k=1, \ldots, i}\left|a_{k}\right| \sum_{k=1}^{i}|| u_{n}\left(t_{k}\right)\right|^{p-2} u_{n}\left(t_{k}\right)-\left|u\left(t_{k}\right)\right|^{p-2} u\left(t_{k}\right) \mid
\end{aligned}
$$

dividing the last inequality by $\|v\|$, we obtain 


$$
\begin{aligned}
\left\|F^{\prime}\left(u_{n}\right)-F^{\prime}(u)\right\|_{*} \leq & \|r\|_{\infty}\left\|\left|u_{n}^{\prime}\right|^{p-2} u_{n}^{\prime}-\left|u^{\prime}\right|^{p-2} u^{\prime}\right\|_{L^{\frac{p}{p-1}}} \\
& +c_{p}\|s\|_{\infty}\left\|\left|u_{n}\right|^{p-2} u_{n}-|u|^{p-2} u\right\|_{L^{\frac{p}{p-1}}} \\
& +\left.c_{\infty} \max _{k=1, \ldots, i}\left|a_{k}\right| \sum_{k=1}^{i}|| u_{n}\left(t_{k}\right)\right|^{p-2} u_{n}\left(t_{k}\right) \\
& -\left|u\left(t_{k}\right)\right|^{p-2} u\left(t_{k}\right) \mid,
\end{aligned}
$$

as in Proposition 3.3, we show that $\left|u_{n}^{\prime}\right|^{p-2} u_{n}^{\prime} \longrightarrow\left|u^{\prime}\right|^{p-2} u^{\prime}$ in $L^{\frac{p}{p-1}}([0,1])$ and $\left|u_{n}\right|^{p-2} u_{n} \longrightarrow|u|^{p-2} u \quad$ in $\quad L^{\frac{p}{p-1}}([0,1])$ and we also have $\left.\sum_{k=1}^{i}|| u_{n}\left(t_{k}\right)\right|^{p-2} u_{n}\left(t_{k}\right)-\left|u\left(t_{k}\right)\right|^{p-2} u\left(t_{k}\right) \mid \longrightarrow 0 \quad$ as $n \longrightarrow+\infty$.

Which implies the continuity of $F^{\prime}$. The proof of the continuity of $G^{\prime}$ is the same as $F^{\prime}$.

On the other hand, from (3.14), we have $\left\langle F^{\prime}(u), u\right\rangle>0$ and so $\inf _{u \in S_{F}}\left\langle F^{\prime}(u), u\right\rangle>0$, also by (3.12) the functions $F, G$ are even and $F(0)=$ $G(0)=0$. Finally by Theorem 3.1 , there exists $c_{0}>0$ such that $F(u) \geq$ $c_{0}\|u\|^{p}$ that implies $\lim _{t \longrightarrow \infty} F(t u)=+\infty$.

Proposition 3.6. Let $F$ be defined in (3.12), then $F^{\prime}$ satisfies $\left(H_{3}\right)$.

Proof. We have already shown that $B=\frac{1}{p} F^{\prime}$ is continuous and bounded in Proposition 3.5. Now, it remains to show that $B$ satisfies the condition $\left(S_{0}\right)$. This means, if $\left\{u_{n}\right\}_{n \in \mathbf{N}}$ is a sequence in $W_{0}^{1, p}([0,1])$ such that remains to show that $B$ satisfies the condition $\left(S_{0}\right)$. This means, if $\left\{u_{n}\right\}_{n \in \mathbf{N}}$ is a sequence in $W_{0}^{1, p}([0,1])$ such that

$$
u_{n} \rightarrow u, B u_{n} \rightarrow v \text { and }\left\langle B u_{n}, u_{n}\right\rangle \longrightarrow\langle v, u\rangle,
$$

for some $v \in\left(W_{0}^{1, p}([0,1])\right)^{*}$ and $u \in W_{0}^{1, p}([0,1])$. By the Sobolev compact embedding theorem, we have $u_{n} \longrightarrow u$ in $L^{p}([0,1])$, and $u_{n}(t) \longrightarrow u(t)$ uniformly for $t \in[0,1]$.

Since $W_{0}^{1, p}([0,1])$ is a reflexive Banach space, then it is isomorphic to a locally uniformly convex Banach space. Thus, to show $u_{n} \longrightarrow u$ in $W_{0}^{1, p}([0,1])$, we need to show $\left\|u_{n}\right\|_{1, p} \longrightarrow\|u\|_{1, p}$. Firstly, remark that $\lim _{n \longrightarrow+\infty}\left\langle B u_{n}-B u, u_{n}-u\right\rangle=\lim _{n \longrightarrow+\infty}\left(\left\langle B u_{n}, u_{n}\right\rangle-\left\langle B u_{n}, u\right\rangle-\left\langle B u, u_{n}-u\right\rangle\right)=0$.

Now, it follows from Proposition 3.4 that 


$$
\begin{gathered}
\left\langle B u_{n}-B u, u_{n}-u\right\rangle-\sum_{k=1}^{i} a_{k}\left(\left|u_{n}\left(t_{k}\right)\right|^{p-1}-\left|u\left(t_{k}\right)\right|^{p-1}\right)\left(\left|u_{n}\left(t_{k}\right)\right|-\left|u\left(t_{k}\right)\right|\right) \\
\geq\left(\left\|u_{n}\right\|_{1, p}^{p}-\|u\|_{1, p}^{p}\right)\left(\left\|u_{n}\right\|_{1, p}-\|u\|_{1, p}\right),
\end{gathered}
$$

and when $u_{n}\left(t_{k}\right) \longrightarrow u\left(t_{k}\right)$ as $n \longrightarrow+\infty$, we have $\sum_{k=1}^{i} a_{k}\left(\left|u_{n}\left(t_{k}\right)\right|^{p-1}-\right.$ $\left.\left|u\left(t_{k}\right)\right|^{p-1}\right)\left(\left|u_{n}\left(t_{k}\right)\right|-\left|u\left(t_{k}\right)\right|\right) \longrightarrow 0$ as $n \longrightarrow+\infty$. So, we deduce that $\left\|u_{n}\right\|_{1, p} \longrightarrow\|u\|_{1, p}$ as $n \longrightarrow+\infty$. Then, $u_{n} \longrightarrow u$ in $W_{0}^{1, p}([0,1])$. Therefore, $B$ satisfies condition $\left(S_{0}\right)$.

Theorem 3.4. ([28]) Let $F, G$ be the two functionals defined on $W_{0}^{1, p}([0,1])$ in (3.16). Then, there exists a nonincreasing sequence of nonnegative eigenvalues $\left\{\mu_{n}\right\}$ obtained from the $(L-S)$ principle such that $\mu_{n} \longrightarrow 0$ as $n \longrightarrow \infty$ where

$$
\mu_{n}=\sup _{H \in \mathcal{C}_{n}} \inf _{u \in H} G(u)
$$

and each $\left\{\mu_{n}\right\}$ is an eigenvalue of $G^{\prime}(u)=\mu F^{\prime}(u)$.

Proof. By the Theorem 3.3-(5), we have the existence of such a sequence $\left\{\mu_{n}\right\}$. To verify (3.18) we observe, using (3.12), (3.13) and (3.14), that

$$
\mu_{n}=\mu_{n} F\left(u_{n}\right)=\mu_{n}\left\langle B u_{n}, u_{n}\right\rangle=\left\langle A u_{n}, u_{n}\right\rangle=G\left(u_{n}\right)=b_{n},
$$

compared this latter with $b_{n}$ in (3.11), we obtain (3.18).

Theorem 3.5. ([28]) Let $F, G$ be the two functionals defined on $W_{0}^{1, p}([0,1])$ in (3.12). Then there exists a nondecreasing sequence of nonnegative eigenvalues $\left\{\lambda_{n}\right\} \longrightarrow \infty$ as $n \longrightarrow \infty, \lambda_{n}=\frac{1}{\mu_{n}}$ where $\left\{\mu_{n}\right\}$ is an eigenvalue of the corresponding equation $G^{\prime}(u)=\mu F^{\prime}(u)$ defined in (3.18).

Proof. $\quad G^{\prime}(u)=\mu F^{\prime}(u)$ is equivalent to

$$
\begin{aligned}
& \int_{0}^{1} m(t)|u(t)|^{p-2} u(t) v(t) d t= \\
& \mu\left(\int_{0}^{1}\left[r(t)\left|u^{\prime}(t)\right|^{p-2} u^{\prime}(t) v^{\prime}(t)+s(t)|u(t)|^{p-2} u(t) v(t)\right] d t\right.
\end{aligned}
$$




$$
+\sum_{k=1}^{i} a_{k}\left|u\left(t_{k}\right)\right|^{p-2} u\left(t_{k}\right) v\left(t_{k}\right), \forall v \in W_{0}^{1, p}([0,1])
$$

or

$$
\begin{gathered}
\int_{0}^{1}\left[r(t)\left|u^{\prime}(t)\right|^{p-2} u^{\prime}(t) v^{\prime}(t)+s(t)|u(t)|^{p-2} u(t) v(t)\right] d t+\sum_{k=1}^{i} a_{k}\left|u\left(t_{k}\right)\right|^{p-2} u\left(t_{k}\right) v\left(t_{k}\right) \\
=\frac{1}{\mu} \int_{0}^{1} m(t)|u(t)|^{p-2} u(t) v(t) d t .
\end{gathered}
$$

By applying Theorem 3.5, we obtain the result.

\subsection{Characterization of the eigenvalues sequence}

By (3.18), the eigenvalues sequence is given by

$$
\frac{1}{\lambda_{n}(m, J)}=\sup _{C \in \mathcal{C}_{n}} \min _{u \in C} \frac{G(u)}{F(u)}, \forall n \in \mathbf{N}
$$

where $J=[0,1]$ and $G(u), F(u)$ are defined in (3.12), $\mathcal{C}_{n}=\left\{H \subset S_{F}\right.$ : $H$ compact, $H=-H, \gamma(H) \geq n\}$,

$S_{F}=\left\{u \in W_{0}^{1, p}([0,1]): \int_{0}^{1}\left[r(t)\left|u^{\prime}(t)\right|^{p}+s(t)|u(t)|^{p}\right] d t+\sum_{k=1}^{i} a_{k}\left|u\left(t_{k}\right)\right|^{p}=1\right\}$.

$\gamma$ is the genus function defined below.

Definition 3.1. ([30]) Let $X$ be a Banach space, and $\Sigma=\{A \subset X$ : $A$ closed, A symmetric $\}$. The genus function $\gamma$ is defined as follows

$$
\begin{aligned}
\gamma: \Sigma & \longrightarrow \mathbf{N} \cup\{\infty\} \\
A & \longmapsto \gamma(A),
\end{aligned}
$$

where $\gamma(A)=\min \left\{k \in \mathbf{N}: \exists \varphi \in C\left(A, \mathbf{R}^{k} \backslash\{0\}\right), \varphi(u)=-\varphi(-u)\right\}$, and we define $\gamma(A)=+\infty$ if the infimum does not exist.

We also define the set $\mathcal{B}_{n}=\left\{C \in \mathcal{C}_{n}: C \subset \Omega\right\}$. Then, (3.19) can be rewritten as

$$
\frac{1}{\lambda_{n}(m, J)}=\sup _{H \in \mathcal{B}_{n}} \min _{u \in H} \int_{0}^{1} m(t)|u(t)|^{p} d t
$$


A simple variational formulation is given by

$$
\frac{1}{\lambda_{n}(m, J)}=\sup _{E \in \mathcal{E}_{n}} \min _{u \in E \cap S_{F}} \int_{0}^{1} m(t)|u(t)|^{p} d t
$$

where $\mathcal{E}_{n}=\left\{E: E\right.$ is a k-dimensional subspace of $\left.W_{0}^{1, p}([0,1])\right\}$.

Definition 3.2. ([18]) A nodal domain is a set defined by $J \backslash Z(u)$, where $Z(u)=\{t \in J: u(t)=0\}$, where $u$ is a solution of the problem (1.10)(1.12).

Lemma 3.2. ([18]) The restriction of a solution $(u, \lambda(m, J))$ of the problem (1.10) - (1.12), on a nodal interval $I$ is an eigenfunction of the same problem on $I$, and we have

$$
\lambda(m, J)=\lambda_{1}\left(m_{/ I}, I\right) .
$$

Proposition 3.7. ([18]) The first eigenvalue $\lambda_{1}(m, J)$ satisfies the strict monotonicity property with respect to the weight $m$ and the domain $J$, i.e., if $m_{1}, m_{2}>0, m_{1}(t) \leq m_{2}(t)$ and $m_{1}(t)<m_{2}(t)$ on a subset of $J$ of non-zero measure for all $t \in J$ and $m_{1}(t)<m_{2}(t)$ in some subset of $J$ of nonzero measure, then

$$
\lambda_{1}\left(m_{2}, J\right)<\lambda_{1}\left(m_{1}, J\right),
$$

and, if $I$ is a strict sub-interval of $J$ such that $m_{/ I}$ is positive, then

$$
\lambda_{1}(m, J)<\lambda_{1}\left(m_{/ I}, I\right) .
$$

Proof. Let $m_{1}$ and $m_{2}$ be such that $m_{1}(t)<m_{2}(t)$, for all $t \in J$. We know previously that the first eigenfunction $u_{1} \in S_{F}$ corresponding to $\lambda_{1}(m, J)$ has no zero in $J$, i.e $u_{1}(t) \neq 0$ for all $t \in J$.

According to (3.20), we have

$$
\begin{aligned}
\frac{1}{\lambda_{1}\left(m_{1}, J\right)} & =\int_{0}^{1} m_{1}(t)\left|u_{1}(t)\right|^{p} d t<\int_{0}^{1} m_{2}(t)\left|u_{1}(t)\right|^{p} d t \\
& \leq \sup _{u \in S_{F}} \int_{0}^{1} m_{2}(t)|u(t)|^{p} d t \\
& =\frac{1}{\lambda_{1}\left(m_{2}, J\right)} .
\end{aligned}
$$


To prove the second inequality, we consider $I$ a sub interval of $J$ and $m_{/ I}$ a weight defined on $I$. Let $u_{1} \in S_{F}$ be a positive eigenfunction associated to $\lambda_{1}\left(m_{/ I}, I\right)$, and denote by $u_{1}$ the extension by zero on $J$. Then, we have

$$
\begin{aligned}
\lambda_{1}\left(m_{/ I}, I\right)= & \int_{I} m(t)\left|u_{1}(t)\right|^{p} d t=\int_{J} m(t)\left|u_{1}(t)\right|^{p} d t \\
& <\sup _{u \in S_{F}} \int_{J} m(t)|u(t)|^{p} d t \\
& =\frac{1}{\lambda_{1}(m, J)} .
\end{aligned}
$$

Therefore, the last strict inequality holds from the fact that $u_{1}$ vanishes in $J \backslash I$. Thus, the latter cannot be a eigenfunction which correspond to the first eigenvalue $\lambda_{1}(m, J)$.

Proposition 3.8. Any solution $(u, \lambda(m, J))$ of problem (1.10) - (1.12) has a finite number of simple zeros.

Proof. We start by showing that $u$ n has a finite number of nodal domains. Assume that there exists a sequence $J_{k}, k \geq 1$, of nodal domains, $I_{l} \cap I_{l^{\prime}}=\emptyset$ for $l \neq l^{\prime}$. Combining Lemma 3.2 with Proposition 3.7, we get

$$
\lambda(m, J)=\lambda_{1}\left(m, J_{k}\right) \geq \lambda_{1}\left(\|m\|_{\infty}, J_{k}\right)=\frac{\lambda_{1}\left(1, J_{k}\right)}{\|m\|_{\infty}}=\frac{\lambda_{1}(1,] 0,1[)}{\|m\|_{\infty}\left(\operatorname{meas}\left(J_{k}\right)\right)^{p}},
$$

where $\|m\|_{\infty}=\max _{t \in[0, T]} m(t)$. Therefore, by (3.25), we get

$$
\text { meas }\left(J_{k}\right) \geq\left(\frac{\lambda_{1}(1,] 0,1[)}{\|m\|_{\infty} \lambda_{1}(m, J)}\right)^{\frac{1}{p}}, \text { for all } k \in \mathbf{N}^{*},
$$

which implies that

$$
\text { meas }(J)=\sum_{k \geq 1} \text { meas }\left(J_{k}\right)=+\infty .
$$

which is a contradiction with the fact that $J$ is bounded. 
Let $\left\{J_{1}, J_{2}, \ldots, J_{k}\right\}$ a finite set of nodal domains for $u$. Put $\left.J_{j}=\right] a_{j}, b_{j}[$, $j \in\{1,2, \ldots, k\}$ where $0 \leq a_{1}<b_{1} \leq a_{2}<b_{2} \leq \ldots \leq a_{k}<b_{k}<1$. It is evidently that the restriction of $u$ on $] 0, b_{1}$ [ is a nontrivial eigenfunction with constant sign that correspond to $\lambda(m, J)$. By the principal maximum, we have $u(t)>0$ or $u(t)<0$ for all $t \in] 0, b_{1}$ [, then $a_{1}=0, u^{\prime}\left(a_{1}\right) \neq 0$ and $u^{\prime}\left(b_{1}\right) \neq 0$. Similarly, we prove that $b_{1}=a_{2}, b_{2}=a_{3}, \ldots, b_{k}=1$. Hence, any eigenfunction associated to an eigenvalue $\lambda(m, J)$ has a finite number of simple zeros.

Proposition 3.9. The eigenfunction $u$ which correspond to the second eigenvalue $\lambda_{2}(m, J)$, has a unique zero $c_{2}$ in $] 0,1\left[\right.$, i.e., $u\left(c_{2}\right)=0$.

Proof. We need to show $u$ changes the sign only once on $J$. Consider $\left.J_{1}=\right] 0, c\left[\right.$ and $\left.J_{2}=\right] c^{\prime}, 1[$, two nodal domains of $u$. By Lemma 3.2, we have

$$
\lambda_{2}(m, J)=\lambda_{1}\left(m_{/ J_{1}}, J_{1}\right)=\lambda_{1}\left(m_{/ J_{2}}, J_{2}\right) .
$$

Assume that $c<c^{\prime}\left(\right.$ similarly for $\left.c^{\prime}<c\right)$, choose $\left.d \in\right] c, c^{\prime}\left[\right.$ and put $\left.I_{1}=\right] 0, d[$ and $\left.I_{2}=\right] d, 1\left[\right.$. Hence, $I_{1} \cap I_{2}=\emptyset$ and it is easy to see that for $k=1,2$, we have $J_{k} \subset I_{k}$ strictly and $m_{/ I_{k}}>0$ on a set of non-zero measure. Thus, by applying the inequality (3.24) in Proposition 3.7, we get

$$
\lambda_{1}\left(m_{/ I_{1}}, I_{1}\right)<\lambda_{1}\left(m_{/ J_{1}}, J_{1}\right)=\lambda_{2}(m, J),
$$

and

$$
\lambda_{1}\left(m_{/ I_{2}}, I_{2}\right)<\lambda_{1}\left(m_{/ J_{2}}, J_{2}\right)=\lambda_{2}(m, J) .
$$

Let $u_{k} \in S_{F}$ be an eigenfunction which correspond to $\lambda_{1}\left(m_{/ I_{k}}, I_{k}\right)$, we have for $k=1,2$

$$
\frac{1}{\lambda_{1}\left(m, I_{k}\right)}=\int_{I_{k}} m(t)\left|u_{k}(t)\right|^{p} d t .
$$

Let $u_{k}$ the extension by zero of $u_{k}$ for $k=1,2$, and consider the two dimensional subspace $E=\operatorname{Vect}\left(u_{1}, u_{2}\right)$. Let $K_{2}=E \cap S_{F} \in W_{0}^{1, p}([0,1])$, evidently $\gamma\left(K_{2}\right)=2$, and remark that

$$
w=\alpha u_{1}+\beta u_{2}, F(w)=1 \Longleftrightarrow|\alpha|^{p}+|\beta|^{p}=1 .
$$

Hence, by (3.20), (3.26), (3.27) and (3.28), we obtain 


$$
\begin{aligned}
\frac{1}{\lambda_{2}(m, J)} & \geq \min _{w \in K_{2}} \int_{J} m(t)|w(t)|^{p} d t \\
& =\min _{w=\alpha u_{1}+\beta u_{2}}\left(|\alpha|^{p} \int_{I_{1}} m(t)\left|u_{1}(t)\right|^{p} d t+|\beta|^{p} \int_{I_{2}} m(t)\left|u_{2}(t)\right|^{p} d t\right) \\
& =\left|\alpha_{0}\right|^{p} \int_{I_{1}} m(t)\left|u_{1}(t)\right|^{p} d t+\left|\beta_{0}\right|^{p} \int_{I_{2}} m(t)\left|u_{2}(t)\right|^{p} d t \\
& >\frac{\left|\alpha_{0}\right|^{p}+\left|\beta_{0}\right|^{p}}{\lambda_{2}(m, J)} \\
& =\frac{1}{\lambda_{2}(m, J)}
\end{aligned}
$$

which give a contradiction. Therefore, $c=c^{\prime}$. Let $v$ a further one eigenfunction which correspond to $\lambda_{2}(m, J)$ such that $v(d)=0$, where $d$ is the unique zero in $] 0,1[$. Assume that $d<c$, then by Lemma 3.2 and (3.24), we obtain

$$
\lambda_{2}(m, J)=\lambda_{1}\left(m_{/] d, 1[},\right] d, 1[)<\lambda_{1}\left(m_{/] c, 1[},\right] c, 1[)=\lambda_{2}(m, J) .
$$

This is a contradiction, then $c=d$.

\section{References}

[1] E. Kruger-Thiemer and S. P. Eriksen, "Mathematical model of sustainedrelease preparations and its analysis", Journal of pharmaceutical sciences, vol. 55, no. 11, pp. 1249-1253, 1966. doi: 10.1002/ jps. 2600551117

[2] L. Nie, Z. Teng, and A. Torres, "Dynamic Analysis of an SIR epidemic model with state dependent pulse vaccination", Nonlinear analysis: real world applications, vol. 13, no. 4, pp. 1621-1629, 2012. doi: 10.1016/j.nonrwa.2011.11.019

[3] X. Meng, Z. Li, and J. J. Nieto, "Dynamic analysis of Michaelis-Menten chemostat-type competition models with time delay and pulse in a polluted environment", Journal of mathematical chemistry, vol. 47, no. 1, pp. 123-144, 2010. doi: 10.1007/ s10910-009-9536-2

[4] A. Conze, J.-M. Lasry, and J. A. Scheinkman, "A system of non-linear functional differential equations arising in an equilibrium model of an economy with borrowing constraints", Annales de l'Institut Henri Poincaré C, analyse non linéaire, vol. 8, no. 5, pp. 523-559, 1991. doi: 10.1016/ s0294-1449(16)30260-8 
[5] S. Liu, J. R. Wang, and Y. Zhou, "Optimal control of noninstantaneous impulsive differential equations", Journal of the Franklin Institute, vol. 354, no. 17, pp. 7668-7698, 2017. doi: 10.1016/j.jfranklin.2017.09.010

[6] V. Covachev, H. Akça, and F. Yeniçerioğlu, "Difference approximations for impulsive differential equations", Applied mathematics and computation, vol. 121, no. 2-3, pp. 383-390, 2001. doi: 10.1016/ s0096-3003(00)00014-x

[7] V. Lakshmikantham, D. D. Bainov, and P. Simeonov, Theory of impulsive differential equations. Singapore: World Scientific, 1989.

[8] D. O'Regan, Existence theory for nonlinear ordinary differential equations. London: Springer, 1997.

[9] J. Kobayashi and M. Ôtani, "An index formula for the degree of (s)+ mappings associated with one-dimensional p-laplacian", Abstract and applied analysis, vol. 2004, no. 11, pp. 981-995, 2004. doi: 10.1155/s1085337504401055

[10] Z. Zhang and J. Wang, "The upper and lower solution method for a class of singular nonlinear second order three-point boundary value problems", Journal of computational and applied mathematics, vol. 147, no. 1, pp. 41-52, 2002. doi: 10.1016/ s0377-0427(02)00390-4

[11] D. Ji, Y. Tian, and W. Ge, "Positive solutions for one-dimensional p-laplacian boundary value problems with sign changing nonlinearity", Nonlinear analysis: theory, methods \& applications, vol. 71, no. 11, pp. 5406-5416, 2009. doi: 10.1016/j.na.2009.04.029

[12] Y. Tian and W. Ge, "Applications of variational methods to boundaryvalue problem for impulsive differential equations", Proceedings of the Edinburgh mathematical society, vol. 51, no. 2, pp. 509-527, 2008. doi: $10.1017 / \mathrm{s} 0013091506001532$

[13] J. Zhou and Y. Li, "Existence and multiplicity of solutions for some Dirichlet problems with impulsive effects", Nonlinear analysis: theory, methods and applications, vol. 71, no. 7-8, pp. 2856-2865, 2009. doi: 10.1016/j.na.2009.01.140

[14] Y. Tian and W. Ge, "Variational methods to Sturm-Liouville boundary value problem for impulsive differential equations", Nonlinear analysis: theory, methods and applications, vol. 72, no. 1, pp. 277-287, 2010. doi: 10.1016/j.na.2009.06.051

[15] J. Sun, H. Chen, and L. Yang, "The existence and multiplicity of solutions for an impulsive differential equation with two parameters via a variational method", Nonlinear analysis: theory, methods and applications, vol. 73, no. 2, pp. 440-449, 2010. doi: 10.1016/j.na.2010. 03.035 
[16] Y. Tian and W. Ge, "Second-order Sturm-Liouville boundary value problem involving the one-dimensional p-laplacian", Rocky mountain journal of mathematics, vol. 38, no. 1, pp. 309-327, 2008. doi: 10.1216/ rmj-2008-38-1-309

[17] Y. Tian and W. Ge, "Multiple positive solutions for a second order Sturm-Liouville boundary value problem with a p-Laplacian via variational methods", Rocky mountain journal of mathematics, vol. 39, no. 1, pp. 325-342, 2009. doi: 10.1216/ rmj-2009-39-1-325

[18] M. Moussa, A. Anane, and O. Chakrone, "Spectrum of one dimensional P-laplacian operator with indefinite weight", Electronic journal of qualitative theory of differential equations, no. 17, pp. 1-11, 2002. doi: 10.14232/ ejqtde.2002.1.17

[19] A. Anane, O. Chakrone, and M. M. Moussa, "Spectrum of the Ap-laplacian operator", Boletim da Sociedade paranaense de matematica, vol. 23, no. 1-2, pp. 115-130, 2005. doi: 10.5269/ bspm.v23i1-2.7466

[20] R. P. Agarwal, H. Lü, and D. O'Regan, "Eigenvalues and the onedimensional P-laplacian", Journal of mathematical analysis and applications, vol. 266, no. 2, pp. 383-400, 2002. doi 10.1006/ jmaa.2001.7742

[21] W. Wang and J. Shen, "Eigenvalue problems of second order impulsive differential equations", Computers and mathematics with applications, vol. 62, no. 1, pp. 142-150, 2011. doi: 10.1016/j.camwa.2011.04.061

[22] O. Muhtarov and S. Yakubov, "Problems for ordinary differential equations with transmission conditions", Applicable analysis, vol. 81, no. 5, pp. 1033-1064, 2002. doi: 10.1080/0003681021000029853

[23] R. K. Amirov, "On Sturm-Liouville operators with discontinuity conditions inside an interval", Journal of mathematical analysis and applications, vol. 317 , no. 1, pp. 163-176, 2006. doi: 10.1016/j.jmaa. 2005.11.042

[24] S. Faydaoğlu and G. S. Guseinov, "An expansion result for a SturmLiouville eigenvalue problem with impulse", Turkish journal of mathematics, vol. 34, no. 3, pp. 355-366, 2010. doi: 10.3906/ mat-0809-34

[25] E. Zeidler, "The Ljusternik-Schnirelman theory for indefinite and not necessarily odd nonlinear operators and its applications", Nonlinear analysis: theory, methods and applications, vol. 4, no. 3, pp. 451-489, 1980. doi: 10.1016/ 0362-546x(80)90085-1 
[26] W. Allegretto and H. Yin Xi, "A Picone's identity for the P-laplacian and applications", Nonlinear analysis: theory, methods and applications, vol. 32, no. 7, pp. 819-830, 1998. doi: 10.1016/s0362-546x(97) 00530-0

[27] M. M. Rao and Z. D. Ren, Theory of Orlicz spaces. New York: M. Dekker, 1991.

[28] A. Lê, "Eigenvalue problems for the P-Laplacian", Nonlinear analysis: theory, methods and applications, vol. 64, no. 5, pp. 1057-1099, 2006. doi: 10.1016/ j.na.2005.05.056

[29] F. E. Browder, "Existence theorems for nonlinear partial differential equations", in Global analysis, S.-S. Chern and S. Smale, Eds. Providence: AMS, 1970, pp. 1-60, 1970.

[30] C. V. Coffman, "A minimum-maximum principle for a class of non-linear integral equations", Journal d'analyse mathématique, vol. 22, no. 1, pp. 391-419, 1969. doi: 10.1007/ bf02786802 


\section{Mohamed Bouabdallah}

Department of Mathematics and Computer, Laboratory Nonlinear Analysis

Faculty of Science,

M ohammed First U niversity,

Oujda,

Morocco

e-mail: bouabdallah.mohamed@ump.ac.ma

\section{Omar Chakrone}

Department of Mathematics and Computer, Laboratory Nonlinear Analysis

Faculty of Science,

M ohammed First U niversity,

Oujda,

Morocco

e-mail: chakrone@yahoo.fr

and

\section{Mohammed Chehabi}

Department of Mathematics and Computer, Laboratory Nonlinear Analysis

Faculty of Science,

M ohammed First U niversity,

Oujda,

Morocco

e-mail: chehb_md@yahoo.fr

Corresponding author 